\title{
Autism spectrum disorder and the applied collaborative approach: a review of community based participatory research and participatory action research
}

\author{
Cheryl A. Wright ${ }^{1}$, Scott D. Wright ${ }^{2 *}$, Marissa L. Diener ${ }^{1}$ and Jacqueline Eaton ${ }^{3}$ \\ *Correspondence: scott.wright@hsc.utah.edu

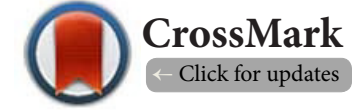 \\ 'Department of Family and Consumer Studies, USA. \\ ${ }^{2}$ Department of Gerontology Interdisciplinary Program, College of Nursing, USA. \\ ${ }^{3}$ College of Nursing University of Utah 220 AEB, USA.
}

\begin{abstract}
The quest to understand ASD is monumental, dramatic and paradigmatically shifting. Research advances in ASD challenge the traditional understanding of autism and call for a "reconceptualization" of autism given the revolutionary impact of recent discoveries. Related to this reconceptualization of autism, are the countervailing forces signaling a shift in the research "agenda" where individuals with ASD are part of the research process-and offer an understanding of autism beyond bench science and traditional scholarship. Although many interpretations of autism remain grounded in the biomedical paradigm, individuals with autism, through narrative self-representations and activities are changing the perspective of autism transforming it from "cure to community." The involvement of individuals with ASD, along with their families, and school and workplace representatives moves research closer to a "communityengaged" endeavor and helps to build a stronger science that is translational and sustainable. This paper examines the role of both community-based participatory research (CBPR) and participatory action research (PAR) in the study of autism issues via the trends analyzed by Scopus in journal publications within an established time-frame of publication dates and specific search analytics. An example of using an ecological model to explore the use of CBPR and PAR in autism research is presented. The goal of this review is to determine trends in publications in these domains and to assist scholars and future researchers to consider identified publications as a part of their plans to use CBPR or PAR designs and ecological models when designing their community engaged research methodology.
\end{abstract}

Keywords: Community-based participatory research, participatory action research, ecological models, Scopus, autism, ASD

\section{Introduction}

Autism spectrum disorder (ASD) is a term that is frequently the focus of current media as well as academic research. A search for autism using the Google search engine, reveals a staggering 20,000,000 results (while the Bing search engine returned 33,600,000 results) (December 24, 2013). Using Amazon.com, a search for books on autism offers nearly 12,262 titles (Dec. 24, 2013). Major findings are emerging daily, and the speed of progress and the sheer challenge of synthesizing and compiling information and keeping current in the autism field is daunting. Edited handbooks examine advances in knowledge regarding autism including the Handbook of Autism and Pervasive Developmental Disorders [84] and the International Handbook of Autism and Pervasive Developmental Disorders [47]. An academic search query using Scopus retrieved 33,838 document results using the following search string using the “Document Search" option:

(autism spectrum disorders) in All Fields

Date Range: Published 1973 to Present ("Present" indicates retrieval date on December 24, 2013).

In the introduction of the Interagency Autism Coordinating Committee Strategic Plan for Autism Spectrum Disorder Research, the authors acknowledged the emerging research was "overwhelming" and that the update would be unable to capture every important advance emerging in the field [37]. The quest to understand ASD is monumental, dramatic and paradigmatically shifting. Research advances in ASD challenge the traditional understanding of autism and call for a "reconceptualization" of autism given the revolutionary impact of recent discoveries [70].

There are many reconceptualizations to consider in theory, research methodology, and clinical practice regarding autism issues. One example would be philosophical challenges to the "mechanistic model" of autism and the positivistic narrative of autism $[\mathbf{9 4 , 9 5}$. Another example would be located in the larger domain of "evidence-based practices" (EBPs) where there is the distinction between comprehensive treatment models (CTMs) and focused intervention practices [96]. In addition, many professionals are focused on the nosology and diagnoses via the revisions found within the DSM-5 and ICD-11 classifications which may alter the landscape of clinical diagnoses, prevalence estimates, autism measures, language, labels, and service provisions for individuals with ASD $[\mathbf{9 7 - 9 9 , 1 0 9 ]}$. These tensions were recently exemplified by the macro-level conceptualizations found within the domain of mental disorders as indicated by 
Wright et al. Journal of Autism 2014,

http://www.hoajonline.com/journals/pdf/2054-992X-1-1.pdf

doi: 10.7243/2054-992X-1-1

the American Psychiatric Association (APA) and the National Institute of Mental Health (NIMH). The NIMH is re-orienting its research away from DSM categories and instead will focus on the Research Domain Criteria project (RDoC), essentially making the DSM-5 and RDoC complementary frameworks for the science of diagnosis [100].

There is also the dynamic zeitgeist of the neurodiversity movement and how the "difference" versus "deficit" label affects research and practice [44], and new efforts focus on "strengthbased" approaches rather than on impairments or deficits $[8,30,55]$. Related to this reconceptualization of autism, are the countervailing forces signaling a shift in the research "agenda" where individuals with ASD are part of the research process - and offer an understanding of autism beyond "bench science" and traditional scholarship $[43,50]$ or as Raymaker \& Nicolaidis [65] have referred to it as "shifting the system." Although many interpretations of autism remain grounded in the biomedical paradigm, individuals with autism, through narrative selfrepresentations and activities are changing the perspective of autism transforming it from "cure to community" $[2,5,6,29,69]$. One example of this transformation is recognition of the concerns and opinions of people who self-identify with autism and Asperger's, especially as it relates to the recent changes in the DSM-5 criteria [101].

The involvement of individuals with ASD, along with their families, school and workplace representatives moves research closer to a "community-engaged" endeavor and helps to build a stronger science that is translational and sustainable [25]. While many conceptualize autism as a biogenic condition, ASD has clear sociocultural and political dimensions that affect how neurotypicals interact with those labeled autistic [68]. There is the call to consider the rights of adults with disabilities to be involved in research to understand their life experiences [49]. This presents respect for families and adults with disabilities and their wish to be engaged in the research process $[2,35,67,72,73]$. The inclusion of people with ASD in meaningful research is ethically important and can provide a positive impact on families and communities $[\mathbf{5 0 , 5 1 , 6 3 ]}$.

This positive impact is the critical translation of results into practice [37]. The IACC has emphasized that autism researchers borrow models to identify feasible and effective community components for successful implementation for the involvement of participants in research design and evaluation [65]. Quality measures can be developed in collaboration with those with ASD to monitor program progress and outcomes.

Intervention research in community settings (e.g., school/ work) with the alignment of the needs of individuals with ASD is a priority [45]. Shared research decision-making will facilitate the sustainability of interventions after the researchers leave [45]. Kasari and Smith note, "Sustainability and success of the treatment is likely greatest when the fit is good within the practice setting. To this end, in addition to a strong evidence base, the intervention must have both community partner buyin to treatment and input into its design and implementation" ( $p$.
263). A stronger presence of community participatory research to complement more traditional research can enhance awareness of autism conditions, issues, and experiences [50]. The two terms most commonly identified with this community-engaged methodology are Community Based Participatory Research (CBPR) and Participatory Action Research (PAR).

This paper has five distinct goals: 1) defining CBPR and $P A R, 2)$ conducting a review of CBPR and PAR research using Scopus indicating selected analytics; 3 ) presenting an overview of research using CBPR and PAR in the domain of autism, 4) providing an example of research that incorporates CBPR and ecological principles, and 5) concluding with insights for future research in the consideration of more inclusiveness of family members and the autism community in the research process. The goal of this review is to assist scholars and future researchers to consider identified publications as a part of their plans to use CBPR or PAR designs when designing their community engaged research methodology.

\section{Community-based participatory research: "building stronger science"}

Autism research may reference "community-based" programs and this often indicates a "real life" intervention versus an "ideal" clinical/lab setting where conditions are controlled $[75,76,82]$. Much of this is community-placed research rather than community-based participatory research (CBPR) or participatory action research (PAR) [41]. The key element of "participatory" of "subjects" in the research design involves stakeholders as active team members at various levels of the research process [42]. This community-based participatory approach is often equated with terms such as, "collaborative inquiry", "community involved", "action research", "communityengaged research" (CE) [25], "participatory research" (PR) [42], or "participatory action research" (PAR) $[\mathbf{2 8 , 4 6 ]}$. The two most commonly used methodology terms are CBPR and PAR and are the focus of this paper.

These approaches are vital research connections, as example, to the study of health care issues $[\mathbf{9 , 1 4 , 2 6 ]}$, inclusive school programs [24], and autism issues in school settings [3]. This paper focuses on terms of "community-based participatory research" (CBPR) and "participatory action research" (PAR) that follow the key foundational works of Israel, Parker, Rowe, Salvatore, Minkler, Lopez et al., [39], and Israel, Eng, Schulz, Minkler and Parker [40], Minkler and Wallerstein [54], and Minkler, Garcia, Rubin, and Wallerstein [53]. There are several definitions of participatory research in circulation $[\mathbf{8 1}, \mathbf{8 5}]$, but this paper highlights the core principles based on the works of Israel et al., [39], and Minkler, Garcia, Rubin, and Wallerstein [53], and the scholarship associated with the journal, Progress in Community Health Partnerships (PCHP) (http://www.press.jhu. edu/journals/progress_in_community_health_partnerships/).

Although a distinct health-dominated focus is related to the core principles, they collectively serve as guidelines for autism CBPR approaches. The eleven principles indicated by 
Wright et al. Journal of Autism 2014,

Minkler, Garcia, Rubin, and Wallerstein [53] for community based participatory research are (and we emphasize the specific importance of \#6 in the list with ecological perspectives): 1) Recognizes community as a unit of identity; 2) Builds on strengths and resources within the community; 3 ) Facilitates a collaborative, equitable partnership in all phases in research, involving an empowering and power-sharing process that attends to social inequalities; 4) Fosters co-learning and capacity building among all partners; 5 ) Integrates and achieves a balance between knowledge generation and intervention for the mutual benefit of all partners; 6 ) Focuses on the relevance of public health problems and on ecological perspectives that attend to the multiple determinants of health; 7) Involves systems development using cyclical and iterative process; 8) Disseminates results to all partners and involves them in a wider dissemination of results; 9) Involves a long-term process and commitment to sustainability; 10 ) Openly addresses issues of race, ethnicity, racism, and social class, and embodies "cultural humility"; 11) Works to ensure research rigor and quality but also seeks to "broaden the bandwidth of validity" with respect to research relevance (emphasis added to \#6 by authors of this paper).

Overall, the literature indicates a rich landscape of CBPR/ PAR into the domains of environmental justice [15], violence prevention [34], intimate partner violence [13], parent education $[60]$, public health $[27,39,85]$, helping parents of people with intellectual disabilities [87], community capacity building and sustainability for social change [32], and in particular, as a framework to reduce health disparities in racial/ethnic groups, rural and underserved populations, $[10,16,17,23$,$36,38,62,80,86]$, and see Tregnago and Cheak-Zamora [78] for a systematic review of disparities in health care for individuals with ASD in the US. We also recommend the annotated bibliography of CBPR works by Julia Stevenson [89], and a review of three models of participatory research [88], and the journal publications offering rigorous methods, process, and outcomes in CBPR [71,91], and books on participatory research with practical applications [31], and health research [9].

In relation to participatory research and autism, the organization, Academic Autistic Spectrum Partnership in Research and Education (AASPIRE: www.aaspire.org), is an excellent example of a collective effort, an academiccommunity partnership to bring, "together people from the three communities: the academic community, the autistic community, and the community of people who provide support and services to autistics." The following sections will review CBPR and PAR Scopus searches in general and then will move to a search of these terms in relation to autism research. Scopus is a large abstract and citation database of research literature and web sources representing 50 million records, 21,000 titles and 5,000 publishers. The database is updated daily and contains over 20,000 peer-reviewed journals, including 2,600 open access journals, 5.5 million conference papers, 390 trade publications, 370 book series,
"Articles-in-Press" from over 3,850 journals, and links to other full-text articles and library resources. The search using Scopus was conducted through a university system (retrieved December 24, 2013) and it is considered to have a robust index and coverage of publications given the triangulation of the collective university library system, including a health sciences library, and a law library.

Community-Based Participatory Research. In order to establish the prevalence and frequency of community-based participatory research, the following search was employed in Scopus in the "Advanced Search". The option in Scopus allows the researcher to use commands to include combinations of search queries that the "Document Search" does not permit. For the purpose of this search the Advanced Search option was employed to search for "Articles" and "Articles in Press" option.

ALL((community-based participatory research)) AND

DOCTYPE(ar) AND DOCTYPE(ip) AND PUBYEAR > 1989

The Scopus search for "community-based participatory research" in ALL fields in journals articles published or in press and limited to publications back to the year 1990 resulted in 13,279 document results and the analytics revealed a steady incremental increase in publications for each year since 1990 to the present search of December 24, 2013. The top five journals for publications in this query were: Progress in Community Health Partnerships (254), American Journal of Public Health (186), American Journal of Community Psychology (134), Health Education and Behavior (116), and Social Science and Medicine (112). When using the TITLE-ABS-KEY default in the "Document Search" option query, the search resulted in 3,234 document results and while Progress in Community Health Partnerships maintained its top journal status for publications (249). The Journal of Health Promotion Practice (79) entered the top five ranking and American Journal of Public Health (75) remained in the top five journals. Both the Journal of Health Care for the Poor and Underserved (53) and Ethnicity and Disease (52) moved into the top 5 journals for publications.

Participatory Action Research. In order to establish the prevalence and frequency of participatory action research, the following search was employed in Scopus in the "Advanced Search" option.

ALL((participatory action research)) AND DOCTYPE(ar) AND DOCTYPE(ip) AND PUBYEAR $>1989$

The Scopus search for "participatory action research" in ALL fields in journals articles published or in press and limited to publications back to the year 1990 resulted in 29,106 document results and the analytics revealed a steady incremental increase in publications for each year since 1990 to the present search date to December 24, 2013. The top five journals for publications in this query was, Progress in Community Health Partnerships (255), Ecology and Society (210), American Journal of Community Psychology (184), Social Science and Medicine (160), and Systematic Practice and Action Research (148). In an attempt to limit the search to the relevant term (participatory action research) in specific fields, the following search was 
Wright et al. Journal of Autism 2014,

http://www.hoajonline.com/journals/pdf/2054-992X-1-1.pdf

doi: 10.7243/2054-992X-1-1

employed in Scopus in the "Advanced Search" option.

TITLE-ABS-KEY ((participatory action research)) AND

DOCTYPE(ar) AND DOCTYPE(ip) AND PUBYEAR > 1989

When using the TITLE-ABS-KEY limiter in the query, the search resulted in 3,211 document results and the American Journal of Community Psychology (57) was indicated as the top journal for document results, with Action Research (47), Systemic Practice and Action Research (35), Progress in Community Health Partnerships Research Education and Action (33), and Educational Action Research (31) rounding out the top five journals for document results.

In summary, the analytics for searching with the terms (community-based participatory research) and (participatory research) revealed a steady increase in document results since 1990 to 2013 and that the publications, Progress in Community Health Partnerships and American Journal of Community Psychology were consistent leading journals for publications in the document results when using either ALL or TITLE-ABS-KEY in the query. The following will be a review of the CBPR and PAR research specific to ASD.

\section{A review of CBPR/ PAR in ASD research}

This review includes sources from the year 1990 to 2013 and online publications found in six databases at the intersect of "autism spectrum disorders" in the domain of "communitybased participatory research" (CBPR) or "participatory action research"(PAR). The literature was systematically reviewed for relevant and peer-reviewed journals, books, book chapters, and selected theses and dissertations. To generate a list of articles (as of January 29,2014) in the first phase, systematic searches were conducted in five electronic databases: PsychINFO, PubMed, Web of Science, Scopus, and ProQuest. The research strategy was complemented by inspecting the included articles and their reference lists. The tactical goal was to utilize these databases to conduct searches in the literature and establish a convergence of relevant publications from multiple database search tools. The review was then grounded in the next phase via a Scopus query algorithm to establish corroboration of relevant publications and to generate analytics for the primary search terms (autism spectrum disorders), (community-based participatory research) and (participatory action research).

The first step was to generate a query equation and request analytics in a stepwise fashion via Scopus for, 1) (community based participatory research) only, and then a separate search and analytics via Scopus for 2) (participatory action research) only to derive a general profile of research activity and trends for both research designs without the additional query parameter of (autism spectrum disorders). The query term, (autism spectrum disorders), was added to the query parameters of (community-based participatory research) and then separately with (participatory action research) via Scopus, thus deriving results for 3 ) (community-based participatory research AND autism spectrum disorders) and then 4) separately for (participatory action research AND autism spectrum disorders). Descriptive data was created on trends and patterns in numerical counts per year, top journal outlets, and top authors associated with the primary search terms as of December, 24 2013. The inclusion and exclusion criteria for searching with the search string (community-based participatory research AND autism spectrum disorders), then in a separate search string, (participatory action research AND autism spectrum disorders) was fairly straightforward and represented the parameters for the query equation associated with the Scopus system in refining results for each query and use of cardinal search terms. For example, when searching Scopus for the search term (participatory action research) or with (community-based participatory research) the query parameters were set in the "Advanced Search" option as including ALL fields, and including only journal articles published or in press and limited to publications back to the year 1990:

ALL(participatory action research) AND (LIMIT-

TO(DOCTYPE, "ar") OR LIMIT-TO(DOCTYPE, "ip")) AND (LIMIT-TO(SRCTYPE, "j")) AND (EXCLUDE(PUBYEAR, 1989)

OR EXCLUDE(PUBYEAR, 1987) OR EXCLUDE(PUBYEAR, 1986)

OR EXCLUDE(PUBYEAR, 1985) OR EXCLUDE(PUBYEAR, 1984)

OR EXCLUDE(PUBYEAR, 1983) OR EXCLUDE(PUBYEAR, 1980)

OR EXCLUDE(PUBYEAR, 1979) OR EXCLUDE(PUBYEAR, 1974))

The Scopus search was refined by way of searching "Article title, Abstract, Keywords," (i.e., TITLE-ABS-KEY) (which is the default setting) as the search parameter yielded a smaller quantitative result in terms of numbers of results or "hits" but without losing significant and relevant search results thus maintaining a better qualitative outcome and a better sensitivity to the "signal" amidst much "noise;" thus, the search parameters in the "Advanced Search" option were outlined in this fashion:

TITLE-ABS-KEY (participatory action research) AND (LIMIT-TO(DOCTYPE, “ar") OR LIMIT-TO(DOCTYPE, "ip")) AND (LIMIT-TO(SRCTYPE, “j”)) AND (EXCLUDE(PUBYEAR, 1989) OR EXCLUDE(PUBYEAR, 1987) OR EXCLUDE(PUBYEAR, 1986) OR EXCLUDE(PUBYEAR, 1985) OR EXCLUDE(PUBYEAR, 1984) OR EXCLUDE(PUBYEAR, 1983) OR EXCLUDE(PUBYEAR, 1980) OR EXCLUDE(PUBYEAR, 1979) OR EXCLUDE(PUBYEAR, 1974)) This tactical decision was used for at each incremental step of the search process so that findings derived for the mini-review that use the ALL field first, and then to the setting of TITLEABS-KEY in the search sequence until the focus of the query with "autism spectrum disorders." For example, in this case,

(TITLE-ABS-KEY (community-based participatory research)) AND (autism spectrum disorders) AND (LIMITTO(DOCTYPE,"ar" ) OR LIMIT-TO(DOCTYPE,"ip" )) AND (EXCLUDE(PUBYEAR, 1987)) AND (LIMIT-TO(SRCTYPE,"j")) the Scopus query focused on searching for the combined terms (community-based participatory research) and (autism spectrum disorders) in existing journal publications or in press with title, abstract, or keywords since 1990. 


\section{Scopus Search: Autism spectrum disorders and participatory action research}

In an attempt to limit the search further to those documents that address both autism spectrum disorders and participatory action research, the following search was employed in Scopus in the "Advanced Search" option.

ALL((autism spectrum disorders AND participatory action research)) AND DOCTYPE(ar) AND DOCTYPE(ip) AND

PUBYEAR $>1989$

The Scopus search for (autism spectrum disorders AND participatory action research) in ALL fields in journal articles published or in press and limited to a Date Range from 1990 to Present resulted in 52 document results and the analytics revealed a steady increase in the total number of documents for this query by year since 1990 until the year 2011 and then a noticeable increase (relative to previous years) to the present search date of December 24, 2013. None of the journals listed under the limiter "Source Title" within this specific search were identified as journals specifically related to autism spectrum disorders. When using the limiter "Article title, Abstract, Keywords," (i.e., TITLE-ABS-KEY) default in the query, the search resulted in 2 document results, but one of two the documents was focused primarily on intellectual disabilities, so we focused on this result for this paper [59].

Scopus Search: Autism spectrum disorders and community-based participatory research In an attempt to limit the search further to those documents that address both autism spectrum disorders and communitybased participatory research, the following search was employed in Scopus in the "Advanced Search" option.

ALL((autism spectrum disorders AND community-based participatory research)) AND DOCTYPE(ar) AND DOCTYPE(ip) AND PUBYEAR $>1989$

The Scopus search for (autism spectrum disorders AND community-based participatory research) in ALL fields in journals articles published or in press and limited to a Date Range from 1990 to Present resulted in 21 document results and the analytics revealed a modest increase in the total number of documents for this query by year since 2008 to the search in December 24, 2013. One journal, Autism Research, was noted in the top five journals for the limiter "Source Title" within this specific search and the publication noted was Pellicano \& Stears (2011) with the title of: "Bridging autism, science and society: Moving toward an ethically informed approach to autism research."

When using the limiter "Article title, Abstract, Keywords," (i.e., TITLE-ABS-KEY) default in the query, the search resulted in 2 document results, and the first noted was $[11,33,61]$.

The second article discovered with the limiter "Article title, Abstract, Keywords," (i.e., TITLE-ABS-KEY) default in the query, the search resulted in 2 document results, and the first noted was [56].

According to Scopus, in December 2013, this article was cited seven times (in six journal articles and in one "letter" in a journal) in a variety of journals related to "intellectual disabilities" but not in "autism" titled or focused journals. It is interesting to note that the Nicolaidis et al., 2011 [56] was cited in another article published by the same group of authors (Nicolaidis et al., 2012) [57] in the journal, Journal of General Internal Medicine, and that the Nicolaidis et al., (2012) [57] article was cited four times since publication. Of further interest is that the Nicolaidis et al., (2012) [57] article was listed separately in the two following search queries when using the ALL fields parameter in the search algorithm for Scopus:

1)ALL((community-based participatory research AND autism spectrum disorders))

2)ALL ((participatory action research AND autism spectrum disorders)). Given the results of the various search queries via Scopus, the exemplar journal articles (listed in descending order by date published - most recent first) and the keywords used for each journal publication $[11,56,57,59]$. When reviewing the reference lists of selected articles and using a fine-grained review of targeted journal publications, referenced theses and dissertations, the following is recommend (listed in descending order by publication date-most recent first) so that readers can appreciate a wider scope of scholarship on CBPR and PAR and ASD issues [18,22,48,58,77].

Some CBPR autism research publications ascribe to an ecological model [79] that fits well with the core CBPR principles highlighted in this paper (see also Minkler, Garcia, Rubin, \& Wallerstein [53]). The ecological model has great potential to reconceptualize autism research by emphasizing the person-environment dynamics of the individual with ASD embedded in reciprocal and temporal relationships of interaction including the family, school, community, and social contexts. The ecological model can also help address the "research-to-practice gap" in autism interventions, especially as there is a premium on testing interventions in "real world settings" and where implementation science may benefit more by emphasizing participatory research methods [102]. The following section will review the ecological model in relation to participatory research in autism.

\section{Grounding autism participatory research in the ecological model}

The ecological paradigm in human development can be traced back to Bronfenbrnner's work in the early 1970's $[103,104]$ and continuing onward with more elaboration and refinement in

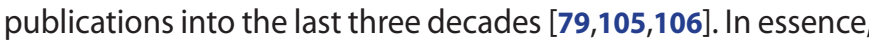
the ecological framework facilitates organizing information about people and their environments in order to understand their interconnections [1]. Voegtle [83] noted that ecological approaches to research acknowledge the resources and barriers at both the individual and community level and that health status is the result of multiple factors, including social, political, and economic systems that can influence behavior. These multiple factors are typically organized as nested systems 
Wright et al. Journal of Autism 2014,

from the individual ("microsystem") interacting with family (or school) outward and expanding through the mesosystem, and to the macrosystem level of social and cultural influences and factors. The ecological model is presented in greater detail by Algood et al., [1] in their examination of factors associated with parenting success for caregivers of children with disabilities. They conclude that successful intervention programs and services will achieve greater efficacy if multiple-level influences are considered and supported. For example, Ravindran \& Meyers [107] use Brofenbrenner's ecological model to examine how cultural beliefs influence families' decision making process about treatments to use - and what outcomes to expect.

There are interconnecting principles and conceptual approaches between CBPR and PAR models, social ecological theory, and the ecological systems approach $[21,79,108]$. For example, many of the community level concerns such as improving health equity and reducing health disparities for underserved populations $[\mathbf{8 5}, \mathbf{8 6}]$ and to facilitate "capacitybuilding" at various levels of intervention (person, family, community) can help with effective policy advocacy at local, state, and national levels [38].

Autism research can be a balance of both the person and interacting environment(s) with research methodology involving researchers and the individual with ASD who is embedded in family and community in which intervention is implemented and educational programs delivered [53].

Voegtle [83] documented the benefits of participatory research embedded in an ecological approach for various age groups, and especially for pediatric and adolescent populations, given their particularly sensitive effects of physical environments and their tendency to be distrustful of outsiders. The ecological model has application when using family-centered approach for working with parents with children with disabilities [1], children and adolescents in mental health family-centered or school settings [21], social communication interventions for children with ASD [64], and school-based behavioral interventions in families with children with ASD [74]. A family-centered care model also examines the perceived challenges of parents with children with ASD [66].

The ecological model emphasizes the person-context process across time periods while recognizing the molecular and genomic-level factors that are associated with autism conditions. Autism researched can be a balance of both the person and interacting environment(s) with research methodology involving researchers and the individual with ASD who is embedded in family and community in which intervention is implemented and educational programs delivered. Furthermore, the complementary approaches of the ecological model and CBPR and PAR recognizes and supports the meaningful participation of the individual with autism in the research process [50]. This perspective is strongly exemplified by the Autism Asperger Partnership in Research and Education (AASPIRE) [56,57].
The ecological model also captures the dynamics of the individual with ASD and the social and cultural forces of influence across the life course. For example, the human development course for the individual with ASD is interconnected with potentially complex interactions over time-from infancy-toddlerhood through the school years and into the adulthood. Lifelong social dynamics include family (parents, grandparents, siblings), school (teachers and peers), friends and peers, post-secondary and occupational influences (coworkers and co-learners, supervisors, customers), formal and informal support (agencies, advocacy groups; community services) and the engagement with social-cultural and citizen activities (non-government and government agencies). The following is an example of an autism community-based participatory research project using the ecological model, that is strength-based and family focused.

\section{CBPR and the ecological model: The iSTAR project} The CBPR and ecological model approaches are central to our autism project that supports the educational interests of youth with ASD in computer-based technology (iSTAR Project). This project is a strengths-based, interest-focused and family-centered program to develop computer-based and technology talent in students with higher-functioning autism [92]. The iSTAR Project uses a CBPR/Ecological research model employing both the experience of an interdisciplinary team of faculty and graduate students from four disciplines (Nursing, Social \& Behavioral Science, Health, and Education) and evaluation feedback from family members (parents, grandparents, siblings) and teachers, special educators and the participating students with ASD. The use of the CBPR approach is a deliberate and sustained effort and the multidisciplinary team continues to use this approach in ongoing research.

Initially, University researchers, educators and Google representatives collaborated on a project regarding Project Spectrum for families and youth with ASD. This was the beginning of a partnership between software developers and the University that still exists today where both groups shared an interest in the merits of 3D design software and training as a viable and efficacious tool to match the visual-spatial talents and abilities of many youth with ASD. The project has offered afterschool and summer camps to teach students with ASD technology design skills. The primary software is SketchUp - used by millions of professionals around the world including architects, engineers, gamers, directors and urban planners. This multidisciplinary research team has the goal of conducting CBPR evidence-based research on the strengths of using 3D design software to spark technology interest in visual-spatial design and facilitate social engagement in students with ASD [92].

The project involves the participating students with ASD and their families in all aspects of the program development and evaluation. Family members (parents, grandparents, siblings) participate in focus groups, lunch discussions, family 
events, and evaluation surveys regarding the evolution of the project $[19,93]$. And the participating students with ASD engage in a video documentary evaluation where they interviewed each other about their participation. Participating students present their 3D designs to their peers and teachers in their regular classrooms and at other community events to demonstrate their knowledge of SketchUp and to show their designs. Teachers and special educators participate as members of our research team and are involved in the continuous evaluation and program development process. The students with ASD, parents and teachers have participated in national conferences where the program was presented. Participating students have also presented their designs at national conferences. Parents and grandparents have reviewed our research papers prior to publication. There is a continuous loop of evaluation and program development that actively involved the participation of family members, students, and community members. There is also active participation from representatives of technology companies where software engineers evaluate student projects on criteria related to creativity and originality [20].

Furthermore, the iSTAR Project continues to examine the psychosocial factors (e.g., social, personal and vocational) that facilitate the interests in 3D design software for the outcome of increased social engagement of youth with ASD. The longer-term goal of the project is sustaining interests and cultivating abilities toward vocational opportunities in the STEM fields, with special focus on the computer technology industry as a viable employment field for youth with ASD transitioning to adulthood. All of these approaches embrace the involvement of families, students with ASD, community members, technology industry representatives, community advocacy groups in program development and evaluation.

A summary of the iSTAR Project and CBPR community outreach activities indicate a robust record related to the socio-ecological/CBPR factors that support and facilitate the technology interests and visual-spatial strengths of youth with ASD [92]. This type of active participation and involvement in the research program enhances social interactions and establish "islands of competencies" for students [12]

The iSTAR Project is a dynamic CBPR research and applied educational model focused on accessibility, outreach strategies, and pedagogical strategies that reflect feedback from families, teachers, technology companies, and students with ASD. These participants serve as consultants and advisory board members, including corporate CEOs, technology (IT) professionals, business, and entrepreneurial experts. The project is grounded in an ecological approach and CBPR methodology, with the participation of our research participants in methodology and solicited feedback for program improvement.

However, in relation to the focus of this paper, this research is not identified as using the terms community-based participatory research or participatory action research in a Scopus search at the more specific TITLE-ABS-KEY query level. These research journal publications were not listed in a Scopus query in either ALL or TITLE-ABS-KEY as parameters for (community-based participatory research AND autism spectrum disorders). However, when using the "Advanced Search" option and employing ALL fields for a Scopus query with the following search string,

ALL(("participatory action research" and "autism spectrum disorders"))

two of our articles $[92,93]$ were in the list of documents retrieved, but not retrieved when using TITLE-ABSTRACTKEYWORDS as the parameter for the search query. The implications of these differential results when using Scopus will be examined in the following discussion section.

\section{Discussion}

The number of publications in the domain of ASD has increased dramatically since the year 2000 based on the analytic results from a Scopus search query. Since the year 2000, there has been a proposed reconceptualization of autism related to diagnosis, research criteria, and the empowerment of individuals with autism to speak directly to the involvement and participation of individuals with ASD in various levels of methodology and translational practices [65]. The potential for cooperation and collaboration has great potential with research design approaches associated with community-based participatory research (CBPR) and/or the participatory action research (PAR). But along with acknowledging the value of such research design practice, it should also be recognized that there are many challenges to the implementation process for CBPR and PAR (e.g., time intensive process) [14,41]. Nevertheless, the use of CBPR practices to add both effectiveness and greater involvement of the autistic individuals, their family system including parents, grandparents, siblings, school system representatives, and advocacy groups in a research design. Sharing and disseminating research findings via the journal publication route may not always result in connecting the scholarship to the relevant electronic databases that could help "bridge" and network the publications to other researchers who have similar research interests. As example, although our research team has implemented a CBPR approach in the research designs, we have discovered that we could improve our networking potential via document retrieval systems by explicitly indicating CBPR in our publications via the title, or the abstract, or the keywords, even though the methodology is described in the body of the published articles, the net result with using Scopus (as example) is that this research is not efficiently "retrieved" in the default search parameters of TITLE-ABS-KEY. It is only when the wider net is cast with using the parameter of ALL fields searched, would these publications become a part of the document retrieved results. The art of finessing the search parameters in databases (e.g., Scopus) has implications for searching for the gold nuggets that scholars are searching for in a wide landscape of results and documents retrieved. For example, a Scopus search query to determine 
Wright et al. Journal of Autism 2014,

http://www.hoajonline.com/journals/pdf/2054-992X-1-1.pdf

doi: 10.7243/2054-992X-1-1

the scope and depth of both research design approaches-CBPR and PAR--in the domain of "autism spectrum disorders" resulted in informative-and illuminating-documents that then led to highly relevant and related publications.

While the number of documents retrieved (in general) are increasing at the intersection of CBPR and PAR and autism spectrum disorders, a fine-grained search (more specifically) in Scopus queries resulted in only a few journal publications in being cited by other authors. The interpretation and provisional analysis is that while several of the publications that were identified in this paper as truly exemplary in the field of CBPR/ PAR and ASD issues, there is little awareness of such research approaches if the nuances of searching techniques and strategies (e.g., (e.g., the parameters of ALL fields versus TITLEABS-KEY) are not fully appreciated and utilized in database queries as exemplified by Scopus. The analytics provided by Scopus for the exemplary publications noted in this paper revealed a citation index ( $\mathrm{h}$-index) with minimal to modest citation activity. This is not the result of these publications as being perceived as having little or nominal "impact" and thus not citation worthy by others in the field; rather, quite the opposite as these authors of the exemplary publications have done their part to clearly and explicitly identify their scholarship as connected to CBPR and PAR designs in the ASD domain. The explanation-and understanding-takes a different tack on the results of searching (and thus a different "reading" of analytics) on the extant literature as exemplified by Scopus.

Those who advocate for a greater use of CBPR and PAR in ASD research designs, and for those who seek to publish and have their research read and cited by others could also benefit by knowing more of the nuances of database searching and the way in which query parameters are manipulated in search algorithms such that discovery and appreciation of work by others is more effectively engineered into the publication itself. In the fine-grained world of search queries by TITLE-ABS-KEY does emerge excellent research in the domain of CBPR and APR and ASD issues - but not all of it. More ASD research strategies of CBPR and PAR exist in the broadest sense of the extant scholarship, but this scholarship may not be evident in journal publications-or cited-or indexed-or retrieved- even when they are primarily related to autism issues. There is an opportunity for a greater depth in creating a network of scholarship that is made more robust by careful attention to the use of selected keywords, abstract descriptors, and even the use of CBPR and PAR in the title of journal publications. In other words, a greater awareness of database parameters and nuances are critical especially when there is so much value, efficiency, and collaborative knowledge in finding the signal in the increasing bandwidth of information.

Our goal is to bring greater awareness of CBPR and PAR research, and to introduce the complementary ecological model approach to researchers who have interests in the autism domain. Individuals on the autism spectrum and their families and communities can be active participants in the research process. These multiple systems of influence over time are key factors in understanding the real life world of individuals with autism. Perhaps we are witnessing the unfolding process in "shifting the system" for autistic people and communities in the research process [65].

\section{Competing interests}

The authors declare that they have no competing interests.

Authors' contributions

\begin{tabular}{|l|c|c|c|c|}
\hline Authors' contributions & CAW & SDW & MLD & JE \\
\hline Research concept and design & $\checkmark$ & $\checkmark$ & $\checkmark$ & $\checkmark$ \\
\hline Collection and/or assembly of data & -- & $\checkmark$ & $\checkmark$ & $\checkmark$ \\
\hline Data analysis and interpretation & -- & $\checkmark$ & $\checkmark$ & -- \\
\hline Writing the article & $\checkmark$ & $\checkmark$ & $\checkmark$ & -- \\
\hline Critical revision of the article & $\checkmark$ & $\checkmark$ & -- & -- \\
\hline Final approval of article & $\checkmark$ & $\checkmark$ & -- & -- \\
\hline Statistical analysis & $\checkmark$ & $\checkmark$ & -- & -- \\
\hline
\end{tabular}

\section{Acknowledgement}

The authors would like to thank and acknowledge Darby Lorraine Fanning, Education Services Librarian, Marriott Library, University of Utah (Salt Lake City, UT) for her valuable professional assistance on the use of Scopus. Support for the literature review was also provided by the 'Health Disparities RITe group' (College of Nursing, University of Utah, SLC, UT).

\section{Publication history}

Editor:Larry Jarrett Barnhill, The University of North Carolina, USA. Received: 02-Nov-2013 Revised: 22-Dec-2013 Accepted: 27-Jan-2014 Published: 07-Feb-2014

\section{References}

1. Algood C. L., Harris C and Hong J. S. Success and challenges for families of children with disabilities: An ecological systems analysis. Journal of Human Behavior in the Social Environment. 2013; 23:126-136. I Article

2. Arnold L. Autism, its relationship to science and to people with the condition. Autonomy, the Critical Journal of Interdisciplinary Autism Studies, 2012; 1. | Article

3. Asberg J, Zander, U. Zander E, Dahlgren A and Sandberg A. Social and individual aspects of classroom learning in students with autism spectrum disorder: an action research pilot study on assessment. European Journa of Special Needs Education. 2012; 27:115-127. | Article

4. Ashwin E, Ashwin C, Rhydderch D, Howells J and Baron-Cohen S. Eagleeyed visual acuity: an experimental investigation of enhanced perception in autism. Biol Psychiatry. 2009; 65:17-21. | Article I PubMed

5. Bagatell N. From cure to community: Transforming notions of autism. Ethos. 2010; 38:33-55. I Article

6. Bagatell N. Engaged moments: mediated action and children with autism in the Classroom Setting. OTJR Occupation, Participation and Health. 2012; 32:258-265. I Article

7. Baron-Cohen S, Emma Ashwin, Chris Ashwin, Teresa Tavassoli and Bhismadev Chakrabarti. The paradox of autism: why does disability sometimes give rise to talent? In N. Kapur (Ed.), The Paradoxical Brain: Cambridge University Press. 2011; 274-288. | Article

8. Baron-Cohen S, Ashwin E, Ashwin C, Tavassoli T and Chakrabarti B. Talent in autism: hyper-systemizing, hyper-attention to detail and sensory hypersensitivity. Philos Trans R Soc Lond B Biol Sci. 2009; 364:1377-83. | Article | PubMed Abstract | PubMed Full Text 
Wright et al. Journal of Autism 2014,

http://www.hoajonline.com/journals/pdf/2054-992X-1-1.pdf

doi: $10.7243 / 2054-992 X-1-1$

9. Blumenthal D. S, DiClemente R. J, Braithwaite R, and Smith S. (2 ${ }^{\text {nd }}$ edition). Community-based participatory health research: Issues, methods, and translation to practice. New York: Springer Publishing Company. 2013. |Book

10. Bogart LM and Uyeda K. Community-based participatory research: partnering with communities for effective and sustainable behavioral health interventions. Health Psychol. 2009; 28:391-3. | Article | PubMed Abstract | PubMed Full Text

11. Brookman-Frazee L, Stahmer AC, Lewis K, Feder JD and Reed S. Building a Research-Community Collaborative to Improve Community Care for Infants and Toddlers at-Risk for Autism Spectrum Disorders. J Community Psychol. 2012; 40:715-734. | Article | PubMed Abstract | PubMed Full Text

12. Brooks R and Goldstein S. Raising resilient children with autism spectrum disorders: Strategies for maximizing their strengths, coping with adversity, and developing a social mindset. New York: McGraw-Hill. 2011. | Book

13. Burke JG, Hess S, Hoffmann K, Guizzetti L, Loy E, Gielen A, Bailey M, Walnoha $A$, Barbee $G$ and Yonas $M$. Translating community-based participatory research principles into practice. Prog Community Health Partnersh. 2013; 7:115-22. | Article | PubMed

14. Cargo $M$ and Mercer SL. The value and challenges of participatory research: strengthening its practice. Annu Rev Public Health. 2008; 29:325-50. | Article | PubMed

15. Chen Y.-W, Milstein T, Anguiano C, Sandoval J and Knudsen L. Challenges and benefits of community-based participatory research for environmental justice: A case of collaboratively examining ecocultural struggles. Environmental Communication: A Journal of Nature and Culture. 2012; 6:403-421. I Pdf

16. Clark L, B. Cardell B, Pett M, Eldredge A, Burley J, Chambless C, and Rothwell $E$. The realities of collecting research data from people with disabilities. In L. Clark (Symposium Organizer), Improving the Health of Persons with Disabilities through Research and Practice. Paper presented at the Annual Western Institute of Nursing Conference, Las Vegas, NV. Conference Paper. 2011. I Website

17. Cardell B. Addressing health inequities in people with intellectual disabilities through community-based participatory research. Dissertation. University of Utah. 2012. I Website

18. Curzon J. With hindsight: An overview of the autism spectrum disorder participatory research project. Kairaranga. 2008; 9:3-8. | Pdf

19. D'Astous V, Wright S.D, Wright C.A and Diener M. L. Grandparents and grandchildren with autism spectrum disorders: Influences on engagement. Journal of Intergenerational Relationships. 2013; 11:134-147. | Article

20. Diener M. L, Wright C. A, Newbold K and Wright S. Adapting a tool to assess visual-spatial creativity in children with autism by building on their strengths. Creativity Research Journal. 2014; 26. | Article

21. Dishion, Thomas J. Stormshak and Elizabeth A. Intervening in children's lives: An ecological, family-centered approach to mental health care. Washington, DC, US: American Psychological Association. 2007:312. | Article

22. Drahota A, Aarons GA and Stahmer AC. Developing the Autism Model of Implementation for autism spectrum disorder community providers: study protocol. Implement Sci. 2012; 7:85. | Article | PubMed Abstract | PubMed Full Text

23. Dulin MF, Tapp H, Smith HA, Urquieta de Hernandez B and Furuseth OJ. A community based participatory approach to improving health in a Hispanic population. Implement Sci. 2011; 6:38. | Article I PubMed Abstract | PubMed Full Text

24. Dymond S. K. A participatory action research approach to evaluating inclusive school programs. Focus on Autism and Other Developmental Disabilities. 2001; 16:54-63. | Article

25. Eder $M$, Tobin JN, Proser M and Shin P. Special issue introduction: building a stronger science of community-engaged research. Prog Community Health Partnersh. 2012; 6:227-30. I Article I PubMed

26. Koshy $\mathrm{E}$, Koshy $\mathrm{V}$ and Waterman $\mathrm{H}$. Action research in healthcare. Los Angeles: SAGE Publications. 2011. | Book
27. Faridi Z, Grunbaum JA, Gray BS, Franks A and Simoes E. Communitybased participatory research: necessary next steps. Prev Chronic Dis. 2007; 4:A70. | Article | PubMed Abstract | PubMed Full Text

28. Gaffney M. Participatory action research: An overview--what makes it tick? Kairaranga. 2008; 9:9-15. | Article

29. Grandin T. Different... Not Less: inspiring stories of achievement and successful employment from adults. Arlington, TX: Future Horizons. 2012. | Book

30. Grandin T and Panek R. The autistic brain: Thinking across the spectrum. New York: Houghton Mifflin Harcourt. 2013. | Book

31. Hacker K. Community-based participatory research. Thousand Oaks, CA SAGE Publications. 2013. | Book

32. Hacker K, Tendulkar SA, Rideout C, Bhuiya N, Trinh-Shevrin C, Savage CP, Grullon M, Strelnick H, Leung $\mathrm{C}$ and DiGirolamo A. Community capacity building and sustainability: outcomes of community-based participatory research. Prog Community Health Partnersh. 2012; 6:349-60. | Article | PubMed Abstract | PubMed Full Text

33. Haine-Schlagel R, Brookman-Frazee L, Janis B and Gordon J. Evaluating a Learning Collaborative to Implement Evidence-Informed Engagement Strategies in Community-Based Services for Young Children. Child Youth Care Forum. 2013; 42: 457-473. | Article | PubMed

34. Hausman AJ, Baker CN, Komaroff E, Thomas N, Guerra T, Hohl BC and Leff SS. Developing measures of community-relevant outcomes for violence prevention programs: a community-based participatory research approach to measurement. Am J Community Psychol. 2013; 52:249-62. | Article | PubMed

35. Heilker P. Autism, rhetoric, and whiteness. Disability Studies Quarterly. 2012; 32. | Article

36. Hoeft TJ, Burke W, Hopkins SE, Charles W, Trinidad SB, James RD and Boyer BB. Building Partnerships in Community-Based Participatory Research: Budgetary and Other Cost Considerations. Health Promot Pract. 2013. I Article I PubMed

37. (IACC), I. A. C. C. IACC Strategic Plan for Autism Spectrum Disorder (ASD) Research - 2012 Update. Retrieved from Retrieved from the U.S. Department of Health and Human Services Interagency Autism Coordinating Committee. 2012. I Website

38. Israel BA, Coombe CM, Cheezum RR, Schulz AJ, McGranaghan RJ, Lichtenstein R, Reyes AG, Clement J and Burris A. Community-based participatory research: a capacity-building approach for policy advocacy aimed at eliminating health disparities. Am J Public Health. 2010; 100:2094-102. | Article | PubMed Abstract | PubMed Full Text

39. Israel BA, Parker EA, Rowe Z, Salvatore A, Minkler M, Lopez J, Butz A, Mosley A, Coates L, Lambert G, Potito PA, Brenner B, Rivera M, Romero $\mathrm{H}$, Thompson B, Coronado $\mathrm{G}$ and Halstead S. Community-based participatory research: lessons learned from the Centers for Children's Environmental Health and Disease Prevention Research. Environ Health Perspect. 2005; 113:1463-71. | Article | PubMed Abstract | PubMed Full Text

40. Israel B. A, Eng E, Shulz A. J and Parker E. Methods for communitybased participatory research for health. San Francisco: San Francisco: Jossey-Bass. 2012. | Book

41. Jacquez F, Vaughn LM and Wagner E. Youth as partners, participants or passive recipients: a review of children and adolescents in community-based participatory research (CBPR). Am J Community Psychol. 2013; 51:176-89. | Article | PubMed

42. Jagosh J, Pluye P, Macaulay A. C, Salsberg J, Henderson J, Sirett E, Bush $P$ and Green L. W. Assessingtheoutcomesofparticipatoryresearch:protoco Iforidentifying,selecting,appraisingandsynthesizingtheliteratureforrealistr eview. ImplementationScience. 2011; 6:24. I Article

43. Jordan CJ and Caldwell-Harris CL. Understanding differences in neurotypical and autism spectrum special interests through Internet forums. Intellect Dev Disabil. 2012; 50:391-402. | Article I PubMed

44. Kapp SK, Gillespie-Lynch K, Sherman LE and Hutman T. Deficit, difference, or both? Autism and neurodiversity. Dev Psychol. 2013; 49:5971. | Article | PubMed

45. Kasari $C$ and Smith T. Interventions in schools for children with autism 
Wright et al. Journal of Autism 2014,

http://www.hoajonline.com/journals/pdf/2054-992X-1-1.pdf

spectrum disorder: methods and recommendations. Autism. 2013; 17:254-67. | Article | PubMed

46. Kemmis S. and McTaggart R. Participatory Action Research: Communicative Action and the Public Sphere. in N.K. Denzin and Y.S. Lincoln (eds) ( 3rd Edition)The Sage Handbook of Qualitative Research, London: Sage Publications. 2005. | Book

47. Matson J. L and Sturmey P. International handbook of autism and pervasive developmental disorders (J. L. Matson \& P. Sturmey Eds.). New York, London: Springer. 2011. | Book

48. Maxam S. L. (2012). Creating an inclusive collegiate learning environment for students on the autism spectrum: A participatory action research study. UMI Dissertation Publishing. UMI Number: 3535981. Unpublished work. Published by ProQuest LLC, 2013.

49. McDonald KE. "We want respect": adults with intellectual and developmental disabilities address respect in research. Am J Intellect Dev Disabil. 2012; 117:263-74. | Article | PubMed

50. Milton D and Bracher M. Autistics speak but are they heard? Medical Sociology Online. 2013; 7:61-69. | Pdf

51. Milton D, Mills $R$ and Pellicano E. Ethics and Autism: Where is the Autistic Voice? Commentary on Post et al., J Autism Dev Disord. 2012. | Article | PubMed

52. Minkler M. Community organizing and community building for health and welfare. New Brunswick, N.J.: Rutgers University Press. 2012. | Book

53. Minkler M, Garcia A. P, Rubin V. Nina and Wallerstein N. Communitybased participatory research: A strategy for building healthy communities and promoting health through policy change. A report to the California Endowment. University of California, Berkeley School of Public Health. Berkeley, CA. 2012. I Website

54. Minkler $M$ and Wallerstein N. (second edition).Community-based participatory research: From process to outcomes. San Francisco, CA: Jossey-Bass. 2008. | Book

55. Mottron L. Changing perceptions: The power of autism. Nature. 2011; 479:33-5. | Article | PubMed

56. Nicolaidis C, Raymaker D, McDonald K, Dern S, Ashkenazy E, Boisclair $C$, Robertson $S$ and Baggs A. Collaboration strategies in nontraditional community-based participatory research partnerships: lessons from an academic-community partnership with autistic self-advocates. Prog Community Health Partnersh. 2011; 5:143-50. | Article | PubMed Abstract | PubMed Full Text

57. Nicolaidis C, Raymaker D, McDonald K, Dern S, Boisclair WC, Ashkenazy $E$ and Baggs A. Comparison of healthcare experiences in autistic and non-autistic adults: a cross-sectional online survey facilitated by an academic-community partnership. J Gen Intern Med. 2013; 28:761-9. | Article | PubMed

58. Olinger $\mathrm{C}$. Working toward agency among the autism community: $\mathrm{A}$ participatory action research study. UMI Dissertation Publishing. UMI Number: 3451908. Unpublished work. Published by ProQuest LLC, 2013.

59. Ostmeyer $\mathrm{K}$ and Scarpa A. Examining school-based social skills program needs and barriers for students with high-functioning autism spectrum disorders using participatory action research. Psychology in the Schools. 2012; 49:932-941. | Article

60. Bermudez Parsai M, Castro FG, Marsiglia FF, Harthun ML and Valdez H. Using community based participatory research to create a culturally grounded intervention for parents and youth to prevent risky behaviors. Prev Sci. 2011; 12:34-47. | Article | PubMed Abstract | PubMed Full Text

61. Parsons S, Charman T, Faulkner R, Ragan J, Wallace $\mathrm{S}$ and Wittemeyer K. Commentary--Bridging the research and practice gap in autism: the importance of creating research partnerships with schools. Autism. 2013; 17:268-80. | Article | PubMed

62. Pett M, Clark L, Cardell B, Eldredge A, Reese S, Carpente J and Hiatt B. Effecting healthy lifestyle change in young adults with intellectual disabilities. In L. Clark (Symposium Organizer), Improving the Health of Persons with Disabilities through Research and Practice. Paper presented at the Annual Western Institute of Nursing Conference, Las
Vegas, NV. Conference Paper, Refereed, Accepted, 04/2011. Conference Paper, Refereed, Presented, 2011. I Website

63. Post SG, Pomeroy J, Keirns CC, Cover VI, Dorn ML, Boroson L, Boroson F, Coulehan A, Coulehan J, Covell K, Kubasek K, Luchsinger E, Nichols S, Parles J, Schreiber L, Tetenbaum SP and Walsh RA. Brief report: Stony Brook Guidelines on the ethics of the care of people with autism and their families. J Autism Dev Disord. 2013; 43:1473-6. | Article | PubMed

64. Prelock P.A and Hutchins T. L. The role of family-centered care in research: Supporting the socil communication of children with autism spectrum disorder. Topics in Language Disorders. 2008; 28:323-339. | Article

65. Raymaker D and Nicolaidis C. Participatory research with autistic communities: Shifting the system. In J. Davidson and M. Orsini, (Eds). Worlds of Autism: Across the Spectrum of Neurological Difference. Minneapolis, MN: The University of Minnesota Press. 2013.

66. Reinke J. S. Families of Children with Autism Spectrum Disorder: The Role of Family-Centered Care in Perceived Family Challenges. (Unpublished doctoral dissertation). University of Minnesota. 2013.

67. Robertson M. The hope of progress. BMC Biol. 2010; 8:39. | Article | PubMed Abstract | PubMed Full Text

68. Rocque B. Mediating Self-Hood: Exploring the Construction and Maintenance of Identity by Mothers of Children Labeled with Autism Spectrum Disorder. Disability and Society. 2010; 25:485-497. | Article

69. Rothstein A. Mental disorder or neurodiversity? The New Atlantis: A Journal of Technology and Society. 2012; 36:99-115. |Article

70. Rutter M. Changing concepts and findings on autism. J Autism Dev Disord. 2013; 43:1749-57. | Article | PubMed

71. Sandoval JA, Lucero J, Oetzel J, Avila M, Belone L, Mau M, Pearson C, Tafoya G, Duran B, Iglesias Rios L and Wallerstein N. Process and outcome constructs for evaluating community-based participatory research projects: a matrix of existing measures. Health Educ Res. 2012; 27:680-90. | Article | PubMed Abstract | PubMed Full Text

72. Santelli B, Singer G.H, DiVenere N, Ginsberg C and Powers L.E. Participatory action research: Reflections on critical incidents in a PAR project. Journal for the Association for Persons with Severe Handicaps. 1998; 23:211-222. | Pdf

73. Sarrett J. C. Autistic human rights - A proposal. Disability Studies Quarterly. 2012; 32. I Article

74. Sears KM, Blair KS, lovannone R and Crosland K. Using the preventteach-reinforce model with families of young children with ASD. $J$ Autism Dev Disord. 2013; 43:1005-16. | Article | PubMed

75. Stock R, Mirenda P and Smith I. M. Comparison of community-based verbal behavior and pivotal response treatment programs for young children with autism spectrum disorder. Research in Autism Spectrum Disorders. 2013; 7:1168-1181. | Article

76. Suhrheinrich J, Stahmer AC, Reed S, Schreibman L, Reisinger E and Mandell D. Implementation challenges in translating pivotal response training into community settings. J Autism Dev Disord. 2013; 43:29706. | Article | PubMed

77. Torch C. E. Autism heard through the lived experiences of siblings: A participatory action research approach. UMI Dissertation Publishing. UMI Number: 3533496 . Unpublished work. Published by ProQuest LLC, 2013; 192.| Article

78. Tregnago $M$ and Cheak-Zamora N.C.A Systematic review of the disparities in health care utilization, Expenditures, and access for individuals with autism spectrum disorders. Research in Autism Spectrum Disorder. 2012; 6:1023-1031. | Article

79. Tudge J. R, Mokrova I, Hatfield B. E and Karnik R. B. Uses and misuses of Bronfenbrenner's bioecological theory of human development. Journal of Family Theory \& Review. 2009; 1:198-210. | Pdf

80. Tumiel-Berhalter LM, Kahn L, Watkins R, Goehle M and Meyer C. The implementation of Good For The Neighborhood: a participatory community health program model in four minority underserved communities. J Community Health. 2011; 36:669-74. | Article | PubMed

81. Viswanathan M, Ammerman A, Eng E, Garlehner G, Lohr KN, Griffith D, 
Wright et al. Journal of Autism 2014,

http://www.hoajonline.com/journals/pdf/2054-992X-1-1.pdf

Rhodes S, Samuel-Hodge C, Maty S, Lux L, Webb L, Sutton SF, Swinson $T$, Jackman $A$ and Whitener L. Community-based participatory research: assessing the evidence. Evid Rep Technol Assess (Summ). 2004; 1-8. | Pdf $\mid$ PubMed.

82. Vismara L. A, Young G. S and Rogers S. J. Community dissemination of the early start denver model: Implications for science and practice. Topics in Early Childhood Special Education. 2013; 32:223-233. I Article

83. Voegtle T. M. A systematic review of community-based participatory research interventions in pediatric and adolescent populations. (Unpublished Master's Thesis). The University of Texas School of Public Health. Houston, TX. 2007.

84. Volkmar F. R, Paul R, Klin A and Cohen D. J. Handbook of autism and pervasive developmental disorders. Hoboken, N.J.: John Wiley. 2005. |Book

85. Wallerstein $\mathrm{N}$ and Duran $\mathrm{B}$. Community-based participatory research contributions to intervention research: the intersection of science and practice to improve health equity. Am J Public Health. 2010; 100 Suppl 1:S40-6. | Article | PubMed Abstract | PubMed Full Text

86. Wallerstein NB and Duran B. Using community-based participatory research to address health disparities. Health Promot Pract. 2006; 7:312-23. | Article | PubMed

87. Walmsley J and Mannan H. Parents as co-researchers: a participatory action research initiative involving parents of people with intellectual disabilities in Ireland. British Journal of Learning Disabilities. 2009; 37:271-276. | Article

88. Weiner $\mathrm{J}$ and McDonald JA. Special issue: three models of communitybased participatory research. LDI Issue Brief. 2013; 18:1-8. | Article | PubMed

89. Westfall J and Stevenson J. A guided tour of community-based participatory research: an annotated bibliography. Ann Fam Med. 2007; 5:185-6. | Article | PubMed Abstract | PubMed Full Text

90. Wilson N, Minkler M, Dasho S, Wallerstein N and Martin AC. Getting to social action: the Youth Empowerment Strategies (YES!) project Health Promot Pract. 2008; 9:395-403. I Article I PubMed

91. Windsor L. C. Using concept mapping in community-based participatory research: A mixed methods approach. Journal of Mixed Methods Research. 2013; 7:274-293. | Article

92. Wright $\mathrm{C}$, Diener $\mathrm{M}$, Dunn L, Wright S.D, Linnell $\mathrm{L}$ and Newbold $\mathrm{K}$ et al., SketchUp: A technology tool to facilitate intergenerational family relationships for children with autism spectrum disorders (ASD). Family and Consumer Sciences Research Journal. 2011; 40:135-149. | Article

93. Wright SD, D'Astous V, Wright CA and Diener ML. Grandparents of grandchildren with autism spectrum disorders (ASD): strengthening relationships through technology activities. Int J Aging Hum Dev. 2012; 75:169-84. | Article | PubMed

94. Verhoeff $B$. The autism puzzle: challenging a mechanistic model on conceptual and historical grounds. Philos Ethics Humanit Med. 2013; 8:17. | Article | PubMed Abstract | PubMed Full Text

95. Verhoff B. Autism in flux: A history of the concept from Leo Kanner to DSM-5. History of Psychiatry. 2013; 24:442-458. | Article

96. Wong C, Odom S.L, Hume K, Cox A.W, Fetting A, Kucharczyk S and Schultz T.R. Evidence-based practices for children, youth, and young adults with autism spectrum disorder. Chapel Hill: The University of North Carolina, Frank Porter Graham Child Development Institute. 2013. | Article

97. Mayes S.D, Black A and Tierney C. D. DSM-5 under-identifies PDDNOS: Diagnostic agreement between the DSM-5, DSM-IV, and Checklist for Autism Spectrum Disorder. Research in Autism Spectrum Disorders. 2013; 7:298-306. | Article

98. Mayes S.D, Calhoun S.L, Murray M.J, Pearl A, Black A and Tierney C.D. Final DSM-5 under identifies mild Autism Spectrum Disorder: Agreement between the DSM-5, CARS, CASD, and clinical diagnoses. Research in Autism Spectrum Disorders. 2014; 8:68-73. I Article

99. Wilson CE, Gillan N, Spain D, Robertson D, Roberts G, Murphy CM, Maltezos S, Zinkstok J, Johnston K, Dardani C, Ohlsen C, Deeley PQ, Craig M, Mendez MA, Happe F and Murphy DG. Comparison of ICD-
10R, DSM-IV-TR and DSM-5 in an adult autism spectrum disorder diagnostic clinic. J Autism Dev Disord. 2013; 43:2515-25. | Article | PubMed

100. Insel T.R and Lieberman J. A. DSM-5 and RDoC: Shared interests. (Press Release). The National Institute of Mental Health. 2013. I Website

101. Linton K. F, Kreck T.E, Sensui L.M and Spillers J. L.H. Opinions of people who self-identify with autism and asperger's on DSM-5 criteria. Research on Social Work Practice. 2014; 24:67-77. I Article

102. Dingfelder HE and Mandell DS. Bridging the research-to-practice gap in autism intervention: an application of diffusion of innovation theory. J Autism Dev Disord. 2011; 41:597-609. | Article | PubMed Abstract | PubMed Full Text

103. Bronfenbrenner U. Developmental research, public policy, and the ecology of childhood. Child Development. 1974; 45:1-5. | Article

104. Bronfenbrenner $U$. Toward an experimental ecology of human development. American Psychologist. 1977; 32:515-531. | Article

105. Bronfenbrenner U. Ecological models of human development. In International Encyclopedia of Education, Vol.3, $2^{\text {nd }}$ edition. Oxford: Elsevier. 1994; 3. | Book

106. Bronfenbrenner U. Ecology of the family as a context for human development: Research perspectives. Developmental Psychologist. 1986; 22:723-742. | Article

107. Ravindran N and Myers B. J. Cultural influences on perceptions of health, Illness, and disability: A review and focus on autism. Journal of Child and Family Studies. 2012; 21:311-319. I Article

108. Stokols D. Translating social ecological theory into guidelines for community health promotion. American Journal of Health Promotion. 1996; 10:282-298. | Pdf

109. Maenner MJ, Rice CE, Arneson CL, Cunniff C, Schieve LA, Carpenter LA, Van Naarden Braun K, Kirby RS, Bakian AV and Durkin MS. Potential Impact of DSM-5 Criteria on Autism Spectrum Disorder Prevalence Estimates. JAMA Psychiatry. 2014. | Article I PubMed

\section{Citation:}

Wright CA, Wright SD, Diener ML and Eaton J. Autism spectrum disorder and the applied collaborative approach: a review of community based participatory research and participatory action research. J Autism. 2014; 1:1. http://dx.doi.org/10.7243/2054-992X-1-1 